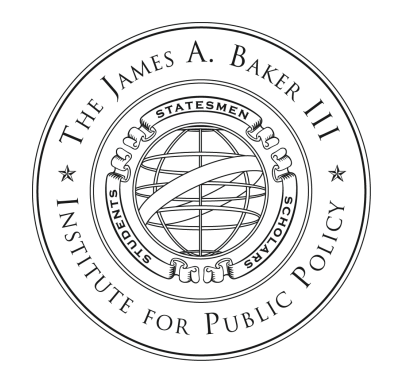

James A. Baker III Institute for Public Policy

RICE UNIVERSITY

\title{
CONSIDERING A NEW INFORMATION ARCHITECTURE FOR THE CITY OF HOUSTON
}

\author{
BY \\ Christopher BRONK, Ph.D. \\ Fellow in Information Technology Policy, James A. Baker III Institute for Public Policy \\ TORY GATTIS \\ LeCturer, Rice Center for EngineERING LEADERSHiP \\ VIVAS KUMAR \\ Student Researcher, Rice University \\ ROBYN MOSCOWITZ \\ Student Researcher, Rice University
}

OCtober 7, 2011 
THESE PAPERS WERE WRITTEN BY A RESEARCHER (OR RESEARCHERS) WHO PARTICIPATED IN A BAKER INSTITUTE RESEARCH PROJECT. WhEREVER FEASIBLE, THESE PAPERS ARE REVIEWED bY OUtSIDE EXPERTS before they ARE RELEASED. HOWEVER, THE RESEARCH AND VIEWS EXPRESSED IN THESE PAPERS ARE THOSE OF THE INDIVIDUAL RESEARCHER(S), AND DO NOT NECESSARILY REPRESENT THE VIEWS OF THE JAMES A. BAKER III INSTITUTE FOR PUBLIC POLICY.

(C) 2011 by the James A. BAker III Institute for P Ublic POlicy of RiCe University

THIS MATERIAL MAY BE QUOTED OR REPRODUCED WITHOUT PRIOR PERMISSION, PROVIDED APPROPRIATE CREDIT IS GIVEN TO THE AUTHOR AND THE JAMES A. BAKER III INSTITUTE FOR PUBLIC POlicy. 


\section{Summary}

For 10 weeks during the summer of 2011, two Rice University student interns from the Rice Center for Engineering Leadership collaborated with faculty from the George R. Brown School of Engineering and the James A. Baker III Institute for Public Policy on a consultative engagement with the City of Houston. The program was initiated after stakeholders in the city's departments of Administrative and Regulatory Affairs and Information Technology indicated an interest in inviting outside talent to look at some of their most pressing issues. Under the supervision of Rice University adjunct faculty member Tory Gattis, the two students interns, Vivas Kumar and Robyn Moscowitz, worked to identify solutions, develop strategy, and prepare software prototypes for adoption by City of Houston offices.

This report details the overarching framework that spurred our interest in bringing software engineering and information management talent to the City's problem set. With budgetary pressures continuing, there is a need for the City to better utilize its information resources and to migrate to more lean, nimble mechanisms that can locate, develop, and integrate the information services it needs. The days of seeking large, highly customized, platform-based information technology (IT) provided at high cost are over for America's large cities because the costs are unsustainable. Some answers will be provided by the proprietary IT market, but others will require unorthodox collaborations between small teams of software developers and government, with the end result being grassroots technical entrepreneurship.

Beyond our philosophical model — what some are calling "open-source government"- — we cover here the major programs undertaken in the summer program, as well as recommendations for future work conducted by Rice University in collaboration with the City. Three major initiatives were undertaken: (1) the development of a wiki platform to capture institutional knowledge; (2) identification of a solution to an email archive and retention issue; and (3) the development of a mobile computing prototype to replace the largely paper-based process currently in place in the Neighborhood Protection Corps. While we do not offer complete solutions to the City's information problems, we have undertaken efforts that might help city planners to think differently about how those challenges might be addressed. 


\section{Open-source Government}

In conducting the first Rice Center for Engineering Leadership-Baker Institute for Public Policy engagement with the City of Houston's Administrative and Regulatory Affairs (ARA) Department, we brought with us a philosophy borrowed from the field of software engineering. This concept is open-source computer software in which, through strong and capable governance, individuals collaborate on projects of utility to a reasonably wide audience and make it available to any who want it. While this open source collaboration baffles economists (as explained in Yochai Benkler's "Coase's Penguin, or Linux and the Nature of the Firm"), the movement has been responsible for the development of most of the software code that makes the Internet work. Our question centers on how the process of a municipality becomes encoded in software as technology makes its way into the business processes of government. We ask: How can public administration become a more open process in which the best ideas prevail rather than "bureaucracy as usual" in which things are done the way they have been done in the past?

The City of Houston would greatly benefit from creating an open-source collaborative in which it engages in limited-scope projects with independent software writers or small agile development teams. The initiative would involve a forum calling upon the public to submit proposals for mobile applications that would serve private citizens' largest needs in relation to their interaction with the City. This would create an environment from which software developers gain ideas for creating applications that reap tremendous benefits for the city. The most notable example of this kind of project is New York City's "NYC BigApps" project.

The NYC BigApps project (http://nycbigapps.com/) invites the general public to submit ideas for mobile applications to help better their experience of New York City. The ideas range from the arts and culture of the city to civic engagements in which the general public contributes to constructing new ideas for planning, services, and other municipal functions. Engagement goes beyond attempting to communicate with an often-faceless bureaucracy and becomes a civic discussion, dominated by residents, but with participation from government. 
How does this work? Novel ideas are voted upon by readers of a "new ideas" website, and New York City releases open source data necessary to accomplish the highest-ranked goals on the website, allowing software developers to create mobile applications over a set period of time. A panel of judges reviews the mobile application submissions and announces winners after judging the applications based on several criteria relating to the usefulness of the applications. For example, the first round of the competition resulted in WayFinder NYC (allows users to find the closest subway entrance) and Big Apple Ed (offers detailed profiles on schools throughout the NYC area).

As the City of Houston aims to rehabilitate neighborhoods throughout its metropolitan area, expand public transportation, and improve essential infrastructure, it should look beyond the boundaries of its in-house workforce by publishing open-source data and allowing third-party developers to compete in developing applications to address technological needs. The City of Houston (hereafter "the City") has a great opportunity to tap into a huge pool of talent by allowing talented software developers and civic organizers (read: volunteers) to create applications based on its citizens' largest needs.

One of the threats to this model of software development is that nearly anybody from throughout the world can access the open-source information that the City decides to release. However, if the City is selective about which pools of data are released to the public, helpful applications can be developed without interfering with sensitive municipal processes.

Another avenue for the City to explore is in spinning out private enterprises from the development of applications in order to bring in an additional source of income. Applications developed to improve business processes that produce positive results and proceeds from investment in civic software could be licensed and sold to other cities throughout the country, and profits from the license sales could be used to bolster the City's bottom line.

This concept of open-source government, where data begets software applications, is not a radical concept. Other cities have moved in this direction, and applications are beginning to grow from early open-source government projects elsewhere, including the "SeeClickFix" mobile 
phone app that is being employed around the country to digitize 311 service systems. This overarching view of the open-source city, in which processes are opened up and data is removed from confusing hierarchical stovepipes, guided the efforts of the Rice University project team in its initial engagement with the City in the summer of 2011.

Below is a summary of the team's efforts during the summer project period, as well as pointers to future directions for building out innovative IT that is the platform for a citywide knowledge strategy that changes managerial, administrative, and technology development processes.

\section{A Wiki of the City}

While the pace of social media development_Facebook, Twitter, YouTube - across the last several years has been rapid, perhaps one of the most important developments in the Internet information sector is Wikipedia. In less than a decade, Wikipedia has grown from a hobbyist project to a threat to traditional sources of information - and a massive, self-correcting resource for storing thousands upon thousands of articles in more than 100 languages. Disappointingly, we in academia did not produce such a resource, but a free encyclopedia now exists. Germane to this report is that the software that makes Wikipedia work also has already found application in government, in the U.S. Intelligence Community, and in cities in Canada and Australia, as well as in many of the world's corporations. Large organizations need repositories of readily available information. Houston is no different.

We entered into the summer engagement with ARA and the City's IT Department with the belief that Enterprise 2.0 tools, especially wikis, should be adopted for the purposes of knowledge management, increased collaboration across all sectors of government, transparency of government proceedings to constituents, and to engage constituents more closely. 


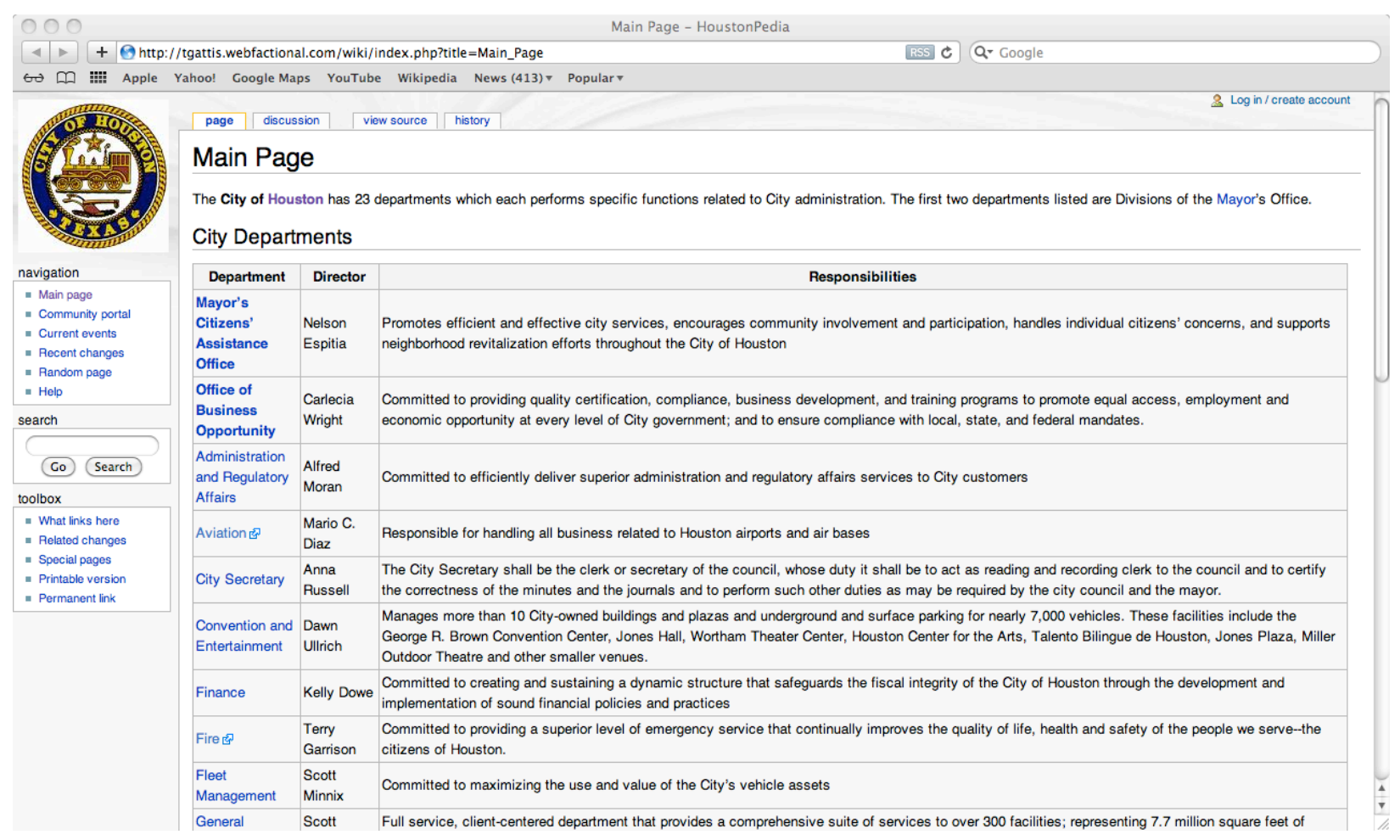

Figure: HoustonPedia prototype

The costs to start-up a wiki are nearly negligible because the City already possesses the necessary servers and databases to run a dynamic wiki. Two kinds of wikis could be useful to the City: internal (where the wiki becomes a repository of knowledge about City policies and procedures, and can only be accessed by City employees) and external (where the wiki becomes a means by which citizens from the City collaborate with government).

By implementing a wiki platform upon which employees can collaborate on documents, the City can reduce server space utilization and increase general efficiency. An internal wiki will also be effective in mitigating the effects of employee turnover by serving as a central collection of the City's internal knowledge.

\section{Assessment of Wikis}

\section{$\underline{\text { Strengths }}$}

A key value of wikis lies in the capacity for several individuals at any time to edit a single instance of a document and changes remain uniform throughout the process of document 
creation and finalization. The simple fact that all users will be working on one document instead of distributing several drafts of documents results in the reduction of server space utilization.

By administering edit-tracking specifications during the wiki creation process, users can track the changes to the document over time so that they can intercede to settle conflicts over content evolution and information management.

\section{Weaknesses}

Wikis do possess some weaknesses that require serious consideration. The most pressing is a phenomenon known as the 90-9-1 Rule. This states that in online communities that base their progress on the interaction and contribution of users: 90 percent of users never contribute actively to the site although utilizing the site for their own gain; 9 percent of users contribute from time to time while utilizing the site for their own knowledge; 1 percent of users are heavy contributors who sacrifice time and energy to maintain the site and actively track the evolution of content on the site.

\section{Other Considerations}

In this situation, one of the motivating factors for the proliferation of the 90-9-1 rule is the fact that employees would not be comfortable with change and initially might not make an effort to learn to work with a wiki platform. Planners must gauge the willingness of City employees to contribute actively to a wiki and to use wikis to accomplish collaborative tasks, and the city's change-management team must undertake the initiative to lead workshops to educate employees about wikis. Leadership in utilizing wikis must begin at the managerial level, as managers must be willing to document institutional knowledge, policies, and procedures before their employees are comfortable doing so. If the City hopes to utilize a wiki to increase citizen participation, an aggressive advertising campaign to inform citizens about the adoption of wikis by the city must be initiated.

The opportunities presented by the adoption of wikis include short- and long-term returns on investment. Employees can save tremendous printing charges by proactively documenting changing institutional policies and procedures on the wikis instead of creating printed versions. 
Over the longer term, institutional knowledge can be used strategically to orient new employees to procedures within the City, thereby reducing the opportunity cost of turnover.

Confidential documents cannot be stored on a wiki, no matter how secure the server, if open access of this manner is enabled. Moreover, if the city were to create an open wiki to provide transparency to private citizens, hackers could easily vandalize the platform and try to propagate their own political/social opinions into the wiki. Clearly, if the City is to move forward in documenting its plans, procedures, and processes via wiki, governance for the platform will be

critical. That said, key stakeholders across the bureaucracy (much the Wikipedia editors) should drive content creation and raise the bar on quality of content.

\section{Email Management}

As we commenced our engagement with ARA and IT, stakeholders in the City expressed concern regarding the management of email content and its archiving and dissemination. The City is not alone in being awash in email. One of the most pressing issues for organizations is coming to grips with how to control distribution, prevent loss, and ultimately delete email correspondence in accordance with local, state, and federal statute and policy. To date, the City has done a solid job of managing the delivery and receipt of email, but it will increasingly need to categorize this correspondence and put into place handling and archiving procedures that protect individual privacy and the interests of the City as it bargains with vendors, suppliers, and other outside organizations.

The City of Houston should move to a single email management and archiving system to manage the emails sent and received by City employees from all levels of the organization in order to better respond to Texas Public Information Act (TPIA) and Open Records Act (ORA) requests, and to better manage the retention of emails between regulated users in the City. Before assessing the different vendors on the market offering email archiving products, we analyzed different email management methods and weighed the benefits and costs of each system in a quantitative user-defined manner. We concluded that vendors offering an enterprise document management system (EDMS) archiving solution would best fit the needs of the City. 
Currently there is need for an archive in which the City must maintain the retention of each email item by specifying repositories for each of the different types of email retention schedules so that emails can be deleted at their expiration. There are 17 different types of retention schedules for emails circulated between regulated users within the City workforce. Furthermore, few of those categories require a lengthy period of retention. Search criteria that isolate a large percentage of each of the 17 types of controlled email must be developed and run on the contents of the archive on a monthly basis so that emails can be categorized for destruction in an organized manner. Basically, a filing system is needed in which some email is shielded from public disclosure, and others marked for disclosure and eventual deletion, much in the way paper records were handled.

The team evaluated the email archive product believed to offer the solution best tailored toward accomplishing the City's most pressing needs: robust search capability, email tagging, and retention policy management. Our solution had the following attributes:

- A current software provider to the City for its email security needs;

- FISMA-compliant ${ }^{1}$ software provider with certified email archiving centers and software tools; and

- Robust search capability to allow the City to perform more optimized searches so that the percentage of relevant emails found for each search space will be greater than that of any of the other software products in this study.

Next steps that must be performed by the City include:

- Collaboration with the vendor to set up a proof of concept and pilot program of the archive within ARA;

- Development of a business justification for the purchase of the archiving solution to be brought forward to City Council; and

- Preparations for transition to a more structured email archive process.

\footnotetext{
${ }^{1}$ FISMA is the Federal Information Security Management Act of 2002, the federal statute required for the computer security of U.S. government information systems.
} 
If an email management solution is to succeed, records management must define search criteria to sequester the largest percentage of emails from each of the retention folders as possible, and must adapt existing City retention policies to the archive, so that email is not inadvertently deleted.

\section{Neighborhood Protection Corps Mobile App}

In addition to looking at how the City could build its institutional knowledge by wiki and find a solution to the email archive issue, our students advocated for a mobile application that would harness the power of contemporary smartphones for data collection and processing problems. After canvassing areas in need of such an application, our team began working with the City's Neighborhood Protection Corps (NPC). The NPC's role of locating and reporting blighted properties is an important public service that prevents crime and enhances public safety.

We concluded that the NPC's current case management process was not efficient and identified the following goals:

- The backlog of requests must be addressed;

- Repetitive activities should be halted;

- Resource utilization can be reduced;

- Job responsibilities can be combined;

- The data collection interface for NPC data collection requires improved usability; and

- The disconnect between the function of different groups in NPC must be addressed.

The City's IT Department is making a push to move custom-built applications to a standard, web-based platform. Although migration to a new platform will be challenging, NPC should take advantage of this opportunity to reexamine their current business processes, reevaluate their needs, and utilize IT resources. 
In order to better understand the role of the FORMS application, which is used for data collection, in the NPC case-management process, we mapped the business process of NPC from the moment a report is generated to the moment the violations are resolved. We evidenced several areas of improvement for the FORMS application and for the department as a whole. FORMS has certainly been built to handle NPC cases in a logical process; however, improvements should be made in several sectors:

- FORMS should be mobilized to allow officers to input data from the field;

- Job responsibilities should be combined to optimize employee's time;

- Resource utilization should be reduced, resulting in long-term return on investment;

- Repetitive activities should be halted to focus employees' time on reducing backlog of cases;

- FORMS must serve as a bridge between all divisions to optimize performance and limit disconnects; and

- General workflow should be optimized by simplifying the interface and focusing on critical features.

During the team's study of NPC process and data management, we observed the following issues.

- A lengthy process to resolution that involves several stakeholders from all levels of NPC;

- An excessive amount of paper used in order to accomplish redundant tasks throughout the process;

- Each level of the organization performing disparate tasks all linked to the progress of each of the cases over a lengthy period of time;

- Possibilities for information to be lost because of lack of communication between individuals involved; and

- Complexity of the process results in significant lag time between steps, and ultimately a backlog of cases. 


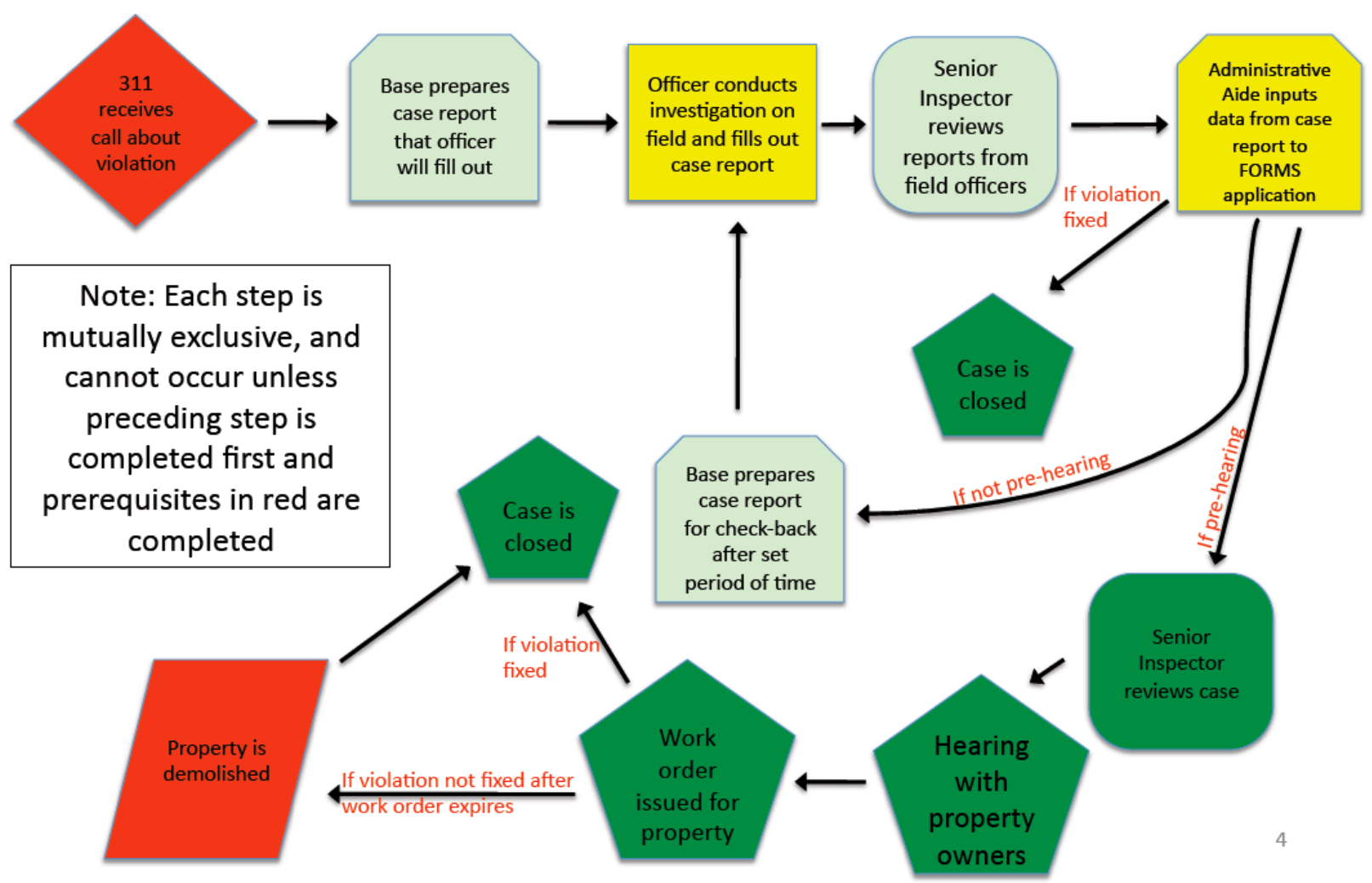

Figure: The NPC Cycle

Regarding the manner in which NPC collects and manages information, we recommend both technical and process changes.

- Allow certain officers to digitally document their reports from tablet computers in the field to reduce paper;

- Reduce officers' office time, send them daily tasking orders electronically for the day so that they can head out to their neighborhoods first thing in the morning to start inspections;

- Permit direct access to the FORMS system from the field on tablets, so an officer can determine whether a property and its violations have already been assessed by other officers so they won't have to repeat inspections;

- Require each officer to create a profile of their activities in FORMS (if officers kept a log of the properties they have assessed within their own profiles in FORMS, they would be 
able to know exactly when they need to make follow-up visits to properties that they have already assessed); and

- Institute a mechanism where the cases for multiple violations still remain so that an officer does not have to go out into the field again and reassess the property when a constituent violation is closed.

We concurred that if NPC officers could reach FORMS from the field, they would not have to call back to one of their local base offices or 311 to verify the details of the properties that they were assessing, and could have all relevant information at their fingertips. As a result, inspectors who are now providing back-end support to on-field officers could also go out to the field and handle cases.
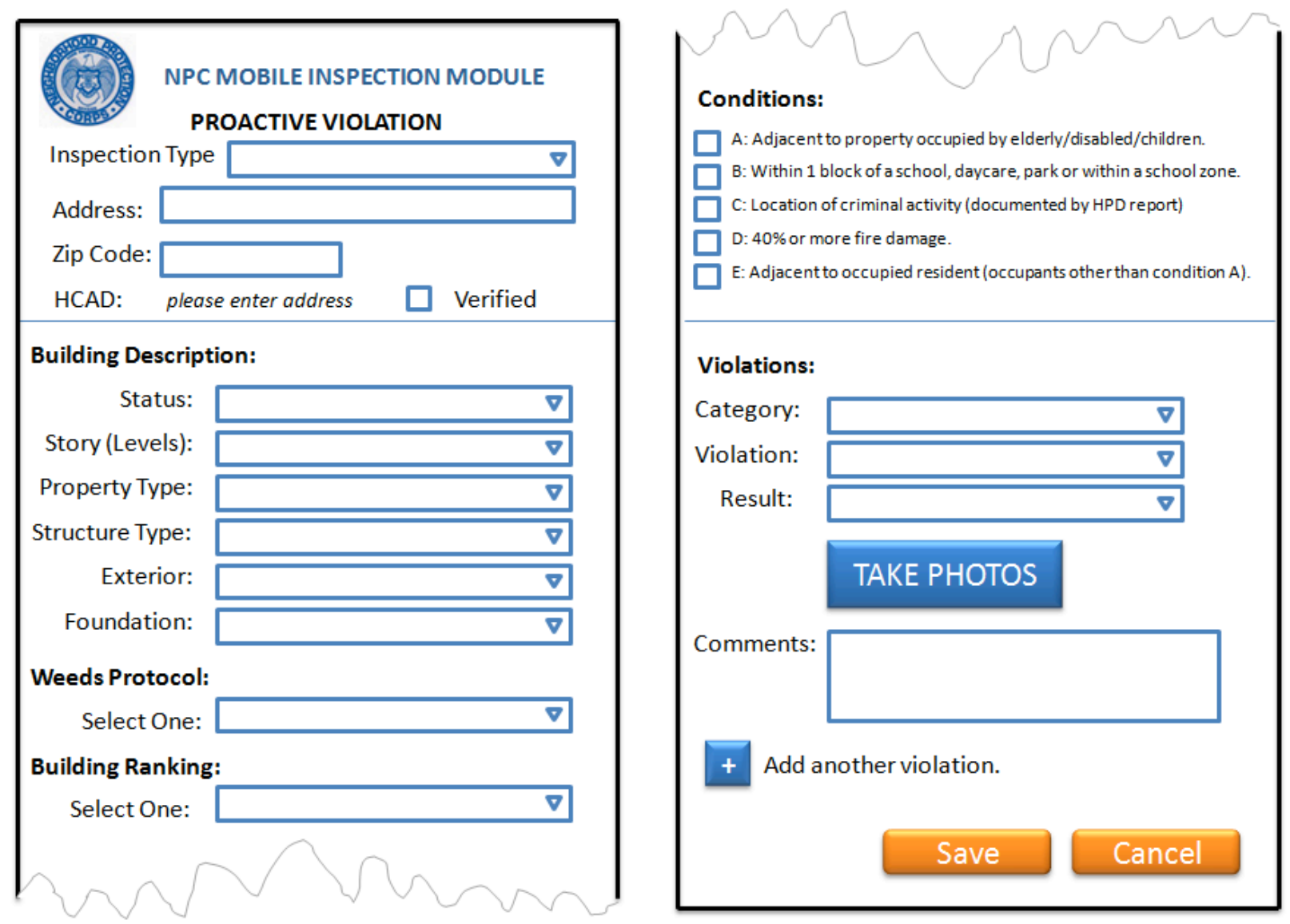

Figure: Prototype NPC Mobile Application for Tablet Platform 


\section{Benefits of Going to the Web}

The benefits of a mobile application include:

- Mobility: Online tools will allow investigators, supervisors, and city officials to monitor and update NPC cases from any web-enabled device resulting in reduced organizational dependence on a centralized base operations location.

- Flexibility: Moving workflow tools to the Internet removes the need for specific types of hardware and software. Moving to a web-based system allows NPC to take advantage of evolving trends in technology and personal devices.

- Sustainability: Going to the web will immediately reduce the amount of paper used by NPC.

- Technology: Web technology, including online tools, is constantly evolving and improving, whereas desktop applications can become antiquated and challenging to update and maintain.

- Transparency: Making data available to city officials and Houston's citizens reflects positively on the organization and increases accountability. It also may reduce direct TPIA/Open Records requests.

\section{Challenges}

For this shift to be successful, a few challenges will need to be addressed proactively:

- Resources: To support a web-based system and tools, NPC would need to make some significant changes to its technological infrastructure; many of these changes could be facilitated by Information Technology Department. NPC must also be prepared to deal with device or system failure.

- Security: Making data and tools accessible from the web requires multiple levels of security to protect NPC data, the City of Houston network, and online users.

- Process Changes: Employees will need training and time to become accustomed to a new system and this transition must be planned and supported by city employees at every level. 
We determined through a rigorous quantitative analysis that stressed the most pressing needs of NPC officers and chief inspectors that a Google Droid tablet would provide the best functionality to meet NPC's goals. In order to determine which mobile device would serve the best interests of NPC field officers, we studied important attributes of the most competitive tablet devices in the market. Five tablets chosen for the final study were amongst the highest rated by critics at PC Magazine and Federal Computer Week, and all had 802.11 Wi-Fi connectivity, 7- to 10-inch screens, Bluetooth capability, and a weight between 600 and 700 grams. All essential features of the five tablets were evaluated according to criteria espoused by chief inspectors at NPC:

- $\quad$ Size of RAM (at least $512 \mathrm{MB}$ )

- Camera (at least 5.0 megapixel)

- $\quad$ Storage (at least $32 \mathrm{~GB}$, with option to expand)

- GPS (preferable)

- Price (maximum $\$ 700$ with all $3 \mathrm{G}$ services included)

Our evaluation found a single model of tablet able to meet these criteria. However, rapid changes in the tablet market will require reevaluation within six months.

\section{Concluding Remarks}

Houston's municipal government is in the unenviable position of having to do more with less. However, this should provide the impetus to invent new means by which it cooperates in publicprivate partnerships or unorthodox collaborations to solve problems. In our work with the City, we identified ample opportunities to begin the job of retooling both process and infrastructure.

Public policy discussion covers many areas and, although retooling the City via IT might not be one of the most exciting ones, it is one that should occur nonetheless. Economist Robert Solow quipped in 1987, "You can see the computer age everywhere but in the productivity statistics." The same could be argued about municipal governments across the country. What we are proposing is a redistribution of resources, effort, and information that may lead to reinvention akin to what Internet-based technologies made in industry in the 1990s. Houston may have a part 
in this shift, or not. We sincerely hope that it does, and that it chooses to seek out ideas from academia, industry, and individuals to change the definition of how IT meets process in the business of government.

\section{Acknowledgments}

The authors wish to thank Alfred Moran, Mark Stinnett, Frank Carmody, Rex Billings, Anthony Elam, Mark Embree, and Amy Kavalewitz for their participation in and support of this project. 